\title{
Analysis of Critical Incidents during Anesthesia in a Tertiary Hospital
}

\author{
Ling Antonia Zeng*, Shin Yi Ng, Sze Ying Thong \\ Department of Anaesthesia, Singapore General Hospital, Singapore City, Singapore \\ Email: *Ainotna@gmail.com
}

Received 14 December 2015; accepted 24 May 2016; published 27 May 2016

Copyright (C) 2016 by authors and Scientific Research Publishing Inc.

This work is licensed under the Creative Commons Attribution International License (CC BY).

http://creativecommons.org/licenses/by/4.0/

(c) (i) Open Access

\section{Abstract}

Introduction: Critical incident monitoring is important in quality improvement as it identifies potential risks to patients by analyzing adverse events or near-misses. Methods: This study analyses the reported incidents in a tertiary hospital over a 4-year period. Results: A total of 441 incidents were reported out of 98,502 anesthetics performed during the study period. Of these incidents, 67 resulted in no harm caused, 116 with unanticipated ICU admissions and 20 mortalities. The odds of having a critical incident increased with ASA status: from an odds ratio of 2.08 (95\% CI: 1.58 to 2.74) for ASA 2 patients compared to ASA1, to OR of 13.70 (5.91 to 31.74) in ASA 5 compared to ASA 1. Critical incidents also have higher odds occurring out of hours (OR 1.7 (1.45 to 2.23) compared to daytime hours $(08: 00-17: 00)$. They occurred most commonly in maintenance phase (142, $32.7 \%)$, followed by induction $(120,27.6 \%)$. The most common types of incidents include airway and respiratory $(110,24.9 \%)$ followed by drug related incidents $(67,15.2 \%)$. Human error was attributed as a significant contributing factor in 276 incidents $(61.5 \%)$ followed by patient factors in 112 incidents (25.4\%). Mitigating factors such as vigilance by staff involved were significant in 136 incidents $(30.3 \%)$. Conclusion: Higher ASA status appears to be the most important factor associated with actual or potential patient harm in our study. Also significant, was time of incident, with incidents more likely out of hours. Critical incident reporting is a valuable part of quality assurance. We should continue to invest in incident reporting, incident analysis and improvement plans.

\section{Keywords}

Critical Incidents, Anaesthesia, Patient Safety, Human Error, Complications

"Corresponding author. 


\section{Introduction}

Critical incident monitoring is important in quality improvement and patient safety as it identifies potential risks to patients by analyzing adverse events or near-misses. The critical incident technique was first described by Flanagan in 1954 to improve safety among military pilots [1], and was subsequently refined for nonmedical and medical uses. Cooper et al. adapted this technique to uncover patterns of frequently occurring incidents in an anesthesia department in 1978 [2]. The original definition of a critical incident by Cooper and colleagues was an occurrence that could have led (if not discovered or corrected in time) or did lead to an undesirable outcome. This was subsequently developed into a national plan in the Australian Incident Monitoring Study [3] [4] in 1988. Currently, there are many established incident monitoring programs worldwide in anesthesia [5] [6] including the American Society of Anesthesiologists (ASA) Committee on Patient Safety and Risk Management, and National Patient Safety Agency in the United Kingdom.

We aimed to review the critical incidents during anesthesia at our institution and analyze the associated factors and outcomes.

\section{Methods}

After obtaining approval from the Institutional Review Board, we analyzed retrospectively collected data of reported critical incidents at our department over a 4-year period from January 1st 2008 to December 31st 2011. Our institution is a tertiary teaching hospital in a city state with 1500 beds, 31 major operating theatres including 2 dedicated emergency theatres, and 54 consultant grade anesthesiologists. The department started electronic reporting of critical incidents from mid-2007.

All critical incidents occurring under the care of an anesthesiologist are self-reported within 72 hours via an electronic risk management system that maintains anonymity. Critical incidents include any occurrence which could have resulted, or did result, in harm to a patient; this includes near misses. Reporting critical incidents is purely voluntary.

The electronic form includes a free text description where a detailed narrative of the incident is included, and also fields which allow users to key in details including time, location, phase of incident, patient demographics, and other details. Factors contributing to the incident, minimizing effects, the outcome of the incident as well as suggested corrective strategies are also part of the form. These reports were presented and discussed at department meetings to identify changes to processes with the goal to improve patient safety and facilitating quality improvement.

The data was exported and the incidents were analyzed using SPSS version 20 (IBM Inc., Chicago, IL, USA). Missing data was traced as far as possible from the incident details, or from the free text narrative. Critical incidents were compared with all anesthetics conducted in the institution in terms of patient demographics, ASA status, emergency status, time of incident, and type of anesthetic. Odds ratios were calculated for these factors.

We also undertook a descriptive analysis of incidents in terms of types of critical incidents, surgical specialty, phase of anesthesia they occurred as well as contributing factors and resulting severity of harm. We further looked into the characteristics of the more serious incidents leading to cardiovascular arrest and perioperative mortality.

\section{Results}

A total of 441 incidents were reported out of 98502 anesthetics performed during the study period. The incidence of reporting of critical incidents was $0.44 \%$.

Table 1 describes the patient demographics, ASA classification, emergency status as well as the time of surgery, and anesthesia technique in relation to all anesthetics conducted. The age of patients ranged from neonates to geriatric patients at 91 years old, the majority were adults and undergoing elective surgery (75.2\%). Further analysis for age of patient was not conducted due to the small volume of pediatric and neonatal surgery in the institution. Although most incidents occurred during elective surgery (75.2\% of all incidents), the majority of anesthetics in our institution are for elective surgery, and the odds ratio compared to emergency surgery is not significant (OR 1.05, 95\% CI: 0.85 to 1.3 ).

Significant findings include ASA status with the odds of having a critical incident increased with increasing ASA status and the time of incident with higher odds of critical incidents occurring out of hours (OR 1.7, 95\% 
Table 1. Characteristics of critical incidents.

\begin{tabular}{|c|c|c|c|}
\hline \multicolumn{3}{|c|}{ Characteristics of critical incidents } & \\
\hline Age & $\begin{array}{l}\text { Distribution for all } \\
\text { anesthetics (\%) }\end{array}$ & $\begin{array}{c}\text { Number of incidents (\%) } \\
\text { total }=441\end{array}$ & \\
\hline Infants $<1$ yo & 0.1 & $1(0.2)$ & \\
\hline Pediatrics & 2.8 & $19(4.4)$ & \\
\hline Adults (18 - 65 yo) & 71.2 & $288(67.3)$ & \\
\hline Geriatrics $>65$ yo & 25.9 & $120(28.0)$ & \\
\hline Gender & $\begin{array}{l}\text { Distribution for all } \\
\text { anesthetics (\%) }\end{array}$ & Number of incidents (\%) & $\begin{array}{l}\text { Odds ratio compared to } \\
\text { female }(95 \% \mathrm{CI})\end{array}$ \\
\hline Male & 49.6 & $231(52.4)$ & 1.18 (0.98 to 1.43$)$ \\
\hline Female & 50.4 & $198(44.9)$ & \\
\hline $\mathrm{ASA}^{\mathrm{a}}$ & $\begin{array}{l}\text { Distribution for all } \\
\text { anesthetics (\%) }\end{array}$ & Number of incidents (\%) & $\begin{array}{l}\text { Odds ratio compared to } \\
\text { ASA } 1(95 \% \mathrm{CI})\end{array}$ \\
\hline 1 & 40.2 & 79 (18.5) & - \\
\hline 2 & 34.6 & $141(32.9)$ & 2.08 (1.58 to 2.74$)$ \\
\hline 3 & 15.4 & $171(40.0)$ & 5.68 (4.35 to 7.43$)$ \\
\hline 4 & 2.0 & $31(7.2)$ & 7.93 (5.22 to 12.05$)$ \\
\hline 5 & 0.2 & $6(1.4)$ & 13.70 (5.91 to 31.74$)$ \\
\hline Status & $\begin{array}{l}\text { Distribution for all } \\
\text { anesthetics (\%) }\end{array}$ & Number of incidents (\%) & $\begin{array}{l}\text { Odds ratio compared to } \\
\text { emergency }(95 \% \mathrm{CI})\end{array}$ \\
\hline Elective & 74.1 & $331(75.2)$ & 1.05 (0.85 to 1.31$)$ \\
\hline Emergency & 25.9 & $110(24.8)$ & - \\
\hline Time of incident & $\begin{array}{l}\text { Distribution of start time } \\
\text { for all anesthetics (\%) }\end{array}$ & Number of incidents (\%) & $\begin{array}{c}\text { Odds ratio compared to } \\
\text { daytime ( } 95 \% \mathrm{CI})\end{array}$ \\
\hline Daytime (08:00-17:00) & 83.7 & $327(74.1)$ & - \\
\hline Out of hours & 16.3 & $114(25.9)$ & 1.79 (1.45 to 2.23$)$ \\
\hline Anesthesia technique $^{\mathrm{b}}$ & $\begin{array}{l}\text { Distribution for all } \\
\text { anesthetics (\%) }\end{array}$ & Number of incidents (\%) & $\begin{array}{l}\text { Odds ratio compared to } \\
\text { GA (95\% CI) }\end{array}$ \\
\hline GA & 83.9 & $358(80.1)$ & - \\
\hline RA & 14.6 & $55(12.3)$ & 088 (0.66 to 1.17$)$ \\
\hline GA \& RA & 0.5 & $18(4.0)$ & 9.38 (5.79 to 15.21$)$ \\
\hline MAC (including line placement) & 0.9 & $12(2.7)$ & 3.05 (1.71 to 5.45$)$ \\
\hline
\end{tabular}

${ }^{a}$ ASA: American Society of Anesthesiologists. Note: ASA 1: normal healthy patient; ASA 2: patient with mild systemic disease; ASA 3: patient with severe systemic disease; ASA 4: patient with severe systemic disease that is a constant threat to life; ASA 5: moribund patient who is not expected to survive without the operation; ${ }^{b}$ Anesthesia technique GA: General Anesthesia, RA: Regional Anesthesia, MAC: Monitored Anesthesia care. 
CI: 1.45 to 2.23$)$ compared to daytime hours (08:00-17:00).

Figure 1 shows the distribution by phase of anesthesia in which the incident took place. The distribution by surgical specialty is shown in Figure 2. General Surgery had the highest number of incidents with 171 (39.0\% of all critical incidents).

The most common types of incidents reported (see Table 2) were airway and respiratory incidents (24.9\%) followed by drug related incidents (15.1\%). Table 3 shows the breakdown of airway and respiratory incidents as well as drug related incidents. Of the 110 airway and respiratory events, most cases resulted in mild to moderate harm, with four incidents resulting in severe harm and no deaths occurred. There were 11 incidents of aspiration, of these patients, six required ICU admission and no deaths occurred.

Details of incidents involving wrong drugs given are presented in Table 4 and wrong dose of drugs in Table 5.

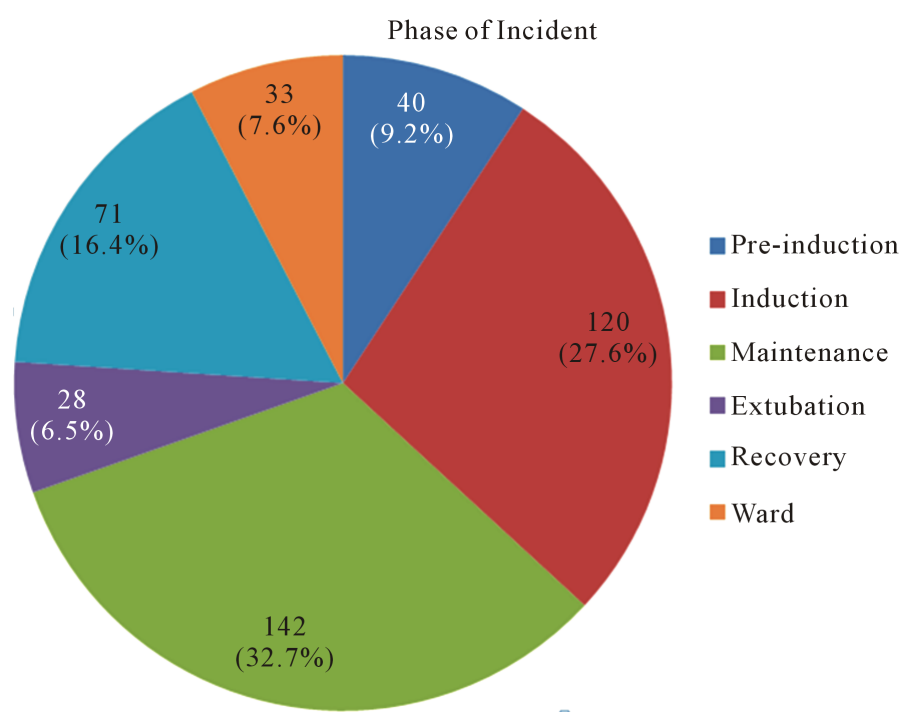

Figure 1. Distribution by phase of incident.

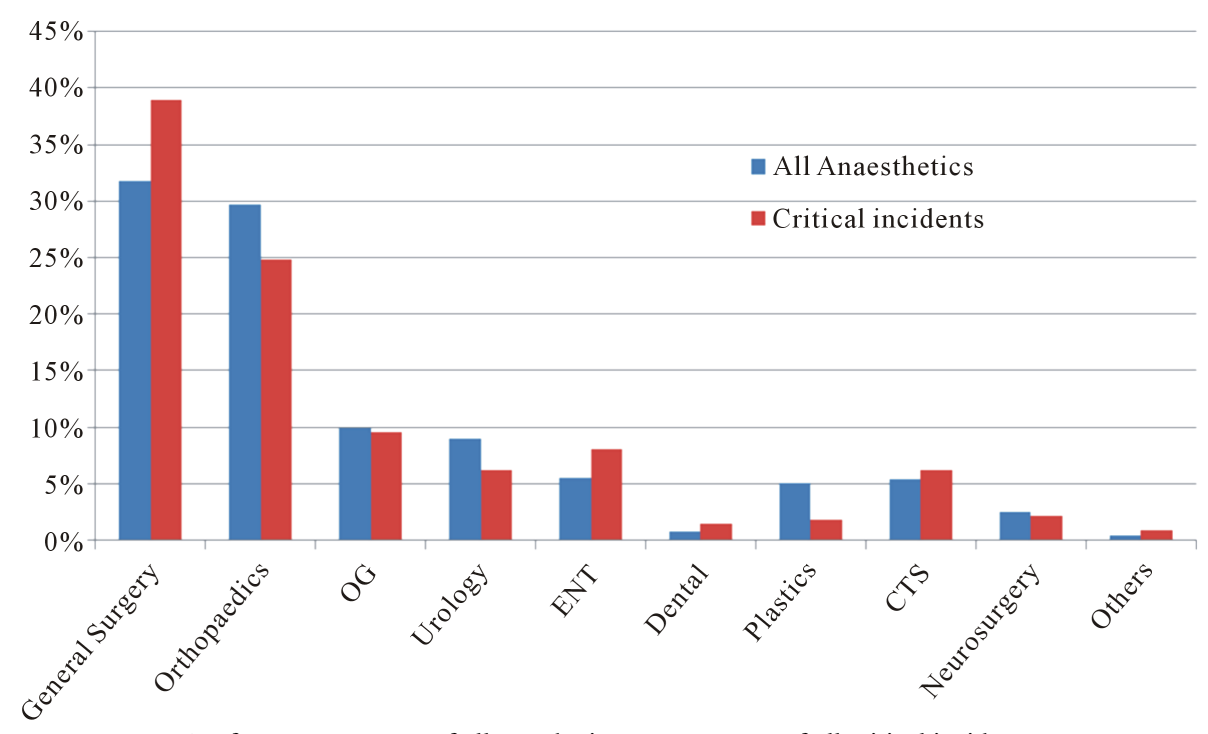

$\%$ refers to percentage of all anesthetics or percentage of all critical incidents

Figure 2. Distribution by surgical specialty. OG: Obstetrics and Gynecology, ENT: Ear, Nose and Throat-referring to Otorhinolaryngology, CTS: Cardiothoracic Surgery. Others: include imaging and diagnostic procedure in radiology, endoscopy, electro-convulsive therapy, cardioversion and radiotherapy. 
Table 2. Types of incidents.

\begin{tabular}{cc}
\hline Type of incidents & Number (\%) \\
\hline Airway and respiratory & $110(24.9)$ \\
Drugs & $67(15.2)$ \\
Surgery related & $53(12.0)$ \\
Procedural related (including Invasive line insertion) & $44(10.0)$ \\
Others & $31(7.0)$ \\
Enanticipated, unpreventable, freak & $28(6.3)$ \\
Infusion, intravascular & $27(6.1)$ \\
Anesthesia related injuries & $21(4.8)$ \\
Cardiac (MI/CCF/arrhythmia) & $19(4.3)$ \\
Case cancellation and administrative & $18(4.1)$ \\
Cerebrovascular accidents & $15(3.4)$ \\
Transfusion related & $4(0.9)$ \\
Total & $4(0.9)$ \\
\end{tabular}

${ }^{\mathrm{a}}$ Includes myocardial infarction, congestive cardiac failure and arrhythmias.

Table 3. Description of common critical incidents.

\begin{tabular}{lc}
\hline \multicolumn{1}{c}{ Type of incident } & Number (\%) \\
\hline Airway and respiratory & 110 \\
Dental & $41(37.3)$ \\
GlideScope related oropharyngeal injuries & $5(4.5)$ \\
Non-GlideScope related oropharyngeal injuries & $3(2.7)$ \\
Aspiration/regurgitation & $11(10.0)$ \\
Failed/unanticipated difficult intubation & $7(6.4)$ \\
Laryngospasm & $4(3.6)$ \\
Negative pressure & $9(8.2)$ \\
Other airway incidents & $21(19.0)$ \\
Respiratory & $9(8.2)$ \\
Drugs & 67 \\
Adverse drug reactions (ADR) & $37(55.2)$ \\
ADR involving vancomycin & $10(14.9)$ \\
ADR involving cephalosporin & $7(10.4)$ \\
Wrong dose & $18(26.9)$ \\
\hline
\end{tabular}


Table 4. Critical incidents involving wrong drugs.

\begin{tabular}{ccl}
\hline Type of incident & Number & \multicolumn{1}{c}{ Description } \\
\hline Unlabelled drug & 2 & Unlabelled morphine used to dilute antibiotics \\
Syringe swap & 3 & $\begin{array}{l}\text { Drugs given mistakenly as Antibiotics: } \\
\text { Morphine, Rocuronium, Phenylephrine }\end{array}$ \\
Drug or ampoule & 6 & $\begin{array}{l}\text { Ergometrine for syntocinon } \\
\text { Ephedrine for heparin for arterial line infusion } \\
\text { Nabstitution }\end{array}$ \\
Natient with drug \\
allergy
\end{tabular}

Table 5. Critical incidents involving wrong dose of drug.

\begin{tabular}{ccl} 
Type of incident & Number & \\
\hline Communication failure & 3 & Somatostatin, Propofol and Cefazolin \\
Infusion pump settings & 3 & Morphine, Atracurium \\
Wrong dilution & 1 & Heparin for dialysis catheter \\
Lack of awareness & 4 & $\begin{array}{l}\text { Overdose of local anaesthetic } \\
\text { Relative overdose of morphine in renal failure }\end{array}$ \\
Inadequate check & 1 & Double dosing of antibiotics \\
\hline
\end{tabular}

Nine out of 30 drug errors occurred in patients undergoing emergency surgery. Contributing factors identified included fatigue or inattention in 15 out of 30 incidents, 10 for lack of knowledge, inexperience or poor judgment, two incidents with inadequate checks or patient assessment and two incidents where time pressure was a factor. Most resulted in no or minimal harm, four resulted in moderate harm, and none in severe harm or death.

Ten incidents of facial skin injury were reported: five after prolonged spine surgery in the prone position and five from tapes used on the face. There were also two cases of Bair Hugger forced air warmer (Augustine Medical, Eden Prairie, MN, USA) associated burns when used without the prescribed blanket, and one case of skin laceration over the forearm. Other anaesthesia related injuries include 5 cases of corneal abrasions after general anaesthesia, and one case of compression related peripheral nerve injury.

Table 6 shows the critical incidents classified by severity of harm as per National Patient Safety Agency definition [7]: No Harm, Low-required extra observation or minor treatment and caused minimal harm, Moderate-moderate increase in treatment and which caused significant but not permanent harm, Severe-result in permanent harm, and Death. There were 67 incidents in which no harm to the patient was caused, 38 critical incidents with cardiovascular arrest, 116 unanticipated ICU admissions and 20 mortalities.

The characteristics of incidents of cardiovascular arrest are described in Table 7. Cardiovascular arrest was defined as any event requiring cardiovascular resuscitation. The two critical incidents involving ASA 2 patients were unexpected, one involving massive blood loss from a radical nephrectomy and the second a hypertensive patient on hydrochlorothiazide with severe hypokalemia resulting in ventricular fibrillation. Details of mortalities within 24 hours of surgery are shown in Table 8.

Human error was attributed as a significant contributing factor in 276 incidents (61.5\%) followed by patient factors (25.4\%). Mitigating factors such as vigilance by staff involved was significant in 136 incidents (30.3\%) and monitor alarms in 72 incidents (16.0\%). 
Table 6. Severity of harm.

\begin{tabular}{cc}
\hline Severity $^{\mathrm{a}}$ & Number (\%) \\
\hline No harm & $67(15.2)$ \\
Low & $180(40.8)$ \\
Moderate & $154(34.9)$ \\
Severe & $20(4.5)$ \\
Death & $20(4.5)$ \\
Total & 441 \\
\hline
\end{tabular}

${ }^{\mathrm{a}}$ As per National Patient Safety Agency definition [7].

Table 7. Characteristics of incidents with cardiovascular arrest.

\begin{tabular}{|c|c|}
\hline Characteristics & Numbers (\%) \\
\hline \multicolumn{2}{|l|}{ Age } \\
\hline Adult & $20(52.6)$ \\
\hline Geriatric (>65 years) & $18(47.3)$ \\
\hline \multicolumn{2}{|l|}{ Gender } \\
\hline Male & $25(65.8)$ \\
\hline Female & $13(34.2)$ \\
\hline \multicolumn{2}{|l|}{ Time of incident } \\
\hline Daytime (08:00-17:00) & $19(50)$ \\
\hline Out of hours & $19(50 \%)$ \\
\hline \multicolumn{2}{|l|}{ ASA } \\
\hline 1 & 0 \\
\hline 2 & $2(5.26)$ \\
\hline 3 & $18(47.3)$ \\
\hline 4 & 12 (31.6) \\
\hline 5 & $6(15.7)$ \\
\hline \multicolumn{2}{|l|}{ Status } \\
\hline Emergency & $26(68.4)$ \\
\hline Elective & $12(31.6)$ \\
\hline \multicolumn{2}{|l|}{ Anaesthesia technique } \\
\hline General & $25(65.7)$ \\
\hline Regional & $11(28.9)$ \\
\hline Monitored anaesthesia care & $2(5.2)$ \\
\hline Total & 38 \\
\hline
\end{tabular}


Table 8. Details of fatal critical incidents.

\begin{tabular}{|c|c|c|c|c|c|c|c|c|}
\hline No & $\begin{array}{l}\text { Age } \\
\text { (yrs.) }\end{array}$ & Sex & ASA & Status & $\begin{array}{l}\text { Anaesthesia } \\
\text { technique }\end{array}$ & Surgery & Medical history & Details \\
\hline 1 & 40 & M & 5 & Emergency & General & Laparotomy & $\begin{array}{l}\text { Polytrauma-Fall from } \\
\text { height. }\end{array}$ & $\begin{array}{l}\text { Arrived in OT in extremis with } \\
\text { unrecordable blood pressure } \\
\text { Developed pulseless electrical activity } \\
\text { (PEA) in OT }\end{array}$ \\
\hline 3 & 36 & M & 5 & Emergency & General & Laparotomy & $\begin{array}{l}\text { Polytrauma-Fall from } \\
\text { height }\end{array}$ & PEA prior to transfer to OT \\
\hline 4 & Young & M & 5 & Emergency & General & Laparotomy & $\begin{array}{l}\text { Polytrauma-Road traffic } \\
\text { accident }\end{array}$ & PEA prior to transfer to OT \\
\hline 5 & 87 & M & 5 & Emergency & General & $\begin{array}{l}\text { Open AAA } \\
\text { repair }\end{array}$ & $\begin{array}{l}\text { Ruptured AAA } \\
\text { HTN, Dyslipidaemia }\end{array}$ & PEA on arrival to OT \\
\hline 6 & 74 & M & 4 & Emergency & General & $\begin{array}{l}\text { Open abdominal } \\
\text { aortic aneurysm } \\
\text { (AAA) repair }\end{array}$ & $\begin{array}{l}\text { Leaking AAA with recent } \\
\text { NSTEMI } \\
\text { HTN, Dyslipidaemia, } \\
\text { Chronic Renal Impairment }\end{array}$ & PEA after aortic crossclamp \\
\hline 7 & 22 & $\mathrm{~F}$ & 4 & Emergency & General & $\begin{array}{l}\text { Pericardial } \\
\text { window }\end{array}$ & $\begin{array}{l}\text { Advanced breast cancer } \\
\text { on chemotherapy } \\
\text { Previous pericardial } \\
\text { window with recollection } \\
\text { of fluid }\end{array}$ & $\begin{array}{l}\text { Intra-operatively: Suction in } \\
\text { pericardial sac drained 1L of thick dark } \\
\text { blood-suspected intracardiac drain, } \\
\text { followed by cardiovascular collapse. }\end{array}$ \\
\hline 8 & 65 & M & 4 & Emergency & General & $\begin{array}{l}\text { Ventricular septal } \\
\text { defect Repair }\end{array}$ & $\begin{array}{l}\text { Post myocardial infarct } \\
\text { Ventricular septal defect }\end{array}$ & $\begin{array}{l}\text { Inferior infarct with ventricular septal } \\
\text { rupture, hypotensive on intra-aortic } \\
\text { ballon pump support preoperatively } \\
\text { Unrepairable Ventricular septal defect }\end{array}$ \\
\hline 9 & 68 & M & 5 & Emergency & General & $\begin{array}{l}\text { Sternotomy, } \\
\text { Haemostasis }\end{array}$ & $\begin{array}{l}\text { Acute Myocardial } \\
\text { Infarction with } \\
\text { pericardial tamponade } \\
\text { HTN, Gout }\end{array}$ & $\begin{array}{l}\text { Failed paricardiocentesis in Emergency } \\
\text { department, developed PEA and } \\
\text { thoracotomy was done in emergency } \\
\text { room releasing large amounts of blood } \\
\text { and clots from pericardial cavity and } \\
\text { open cardiac massage performed. } \\
\text { Developed PEA on transfer to OT }\end{array}$ \\
\hline 10 & 72 & $\mathrm{~F}$ & 4 & Emergency & General & $\begin{array}{c}\text { Open } \\
\text { Cholecystectomy }\end{array}$ & $\begin{array}{l}\text { Acute cholecystitis } \\
\text { ESRF on Peritoneal } \\
\text { dialysis } \\
\text { DM, HTN, Previous } \\
\text { stroke }\end{array}$ & $\begin{array}{l}\text { PEA during intra-operative } \\
\text { manipulation of gallbladder }\end{array}$ \\
\hline 11 & 68 & M & 3 & Emergency & $\begin{array}{c}\text { Combined } \\
\text { Spinal-Epidural }\end{array}$ & $\begin{array}{l}\text { Loop trephine } \\
\text { colostomy }\end{array}$ & $\begin{array}{l}\text { Advanced Rectal Cancer } \\
\text { on palliative radiotherapy } \\
\text { Ischaemic } \\
\text { cardiomyopathy, } \\
\text { previous stroke, DM, } \\
\text { HTN, Dyslipidaemia }\end{array}$ & $\begin{array}{l}\text { Hypotension Intra-op. } \\
\text { In recovery, developed ischemic ECG } \\
\text { changes, followed by ventricular } \\
\text { fibrillation (VF) }\end{array}$ \\
\hline 12 & 78 & $\mathrm{~F}$ & 3 & Emergency & $\begin{array}{c}\text { Local } \\
\text { Anaesthesia }\end{array}$ & Angioplasty & $\begin{array}{l}\text { ESRF, PVD for } \\
\text { angioplasty }\end{array}$ & Arrest from likely bleeding. \\
\hline
\end{tabular}




\section{Continued}

13

41

14

$3 \quad$ Emergency

Spinal

Peripheral

15 53

$\mathrm{M}$

3 Emergency

nerve block

Peripheral nerve block

16

$\begin{array}{llll}71 & \text { M } & 4 & \text { Emergency }\end{array}$

17

$\mathrm{M}$

4

Emergency

Peripheral nerve block

$18 \quad 69 \quad \mathrm{M} \quad 3 \quad$ Elective $\quad$ General

19

65

M

Elective

General

General
Above knee amputation

Left Above Knee

Amputation and

debridement of

right below knee stump

Debridement and fasciotomy

of arm

ectomy and

drainage L2/L3

abscess

Craniotomy and resection of parietal tumour

HTN, Dyslipidaemia

Chronic Smoker,

Colon Cancer status post resection.

Septic shock on

dopamine

Chronic Anaemia,

Hypertension (HTN),

Hypothyroidism

Recent NSTEMI with

Left foot gangrene

DM, Dyslipidaemia,

Depression

left arm

Dyslipidaemia infection

Cervical Myelopathy

Salmonella L2-L4

Osteomyelitis with

psoas abscess
Left leg gangrene

Non-ST Elevation

Myocardial infarction

(NSTEMI)

End Stage Renal Failure

(ESRF) on Haemodialysis,

Diabetes Mellitus (DM),

Intra-operatively haemodynamically stable, an uneventful course in recovery, asystole arrest in general ward 3 hours after.

Forearm thrombophlebitis

Developed hypotension in the ward 3

hours post op,

cardiomyopathy, Chronic Had NSTEMI and hemothorax from renal impairment, DM

Developed PEA in ward

Necrotizing fasciitis of

Given sedation for supraclavicular

ESRF on haemodialysis, approach to brachial plexus block

IHD, previous stroke, Developed hypotension and VF

Atrial fibrillation, HTN, during block

Sepsis from Below knee amputation stump wound

Required conversion to GA due to

NSTEMI complicated by pain.

congestive cardiac failure, Developed ST elevation

DM, HTN, Dyslipidaemia, intraoperatively, followed by

Carotid artery stenosis,

Septic patient with new ischaemic ECG changes before surgery

Prolonged surgery complicated by

blood loss of $2.3 \mathrm{~L}$

PEA at end of surgery.

Post induction developed hypotension then refractory VF

Pulmonary artery injury during pneumonectomy

Attempted going onto

cardiopulmonary bypass however

Left Lung

Pneumonectomy Adenocarcinoma

HTN difficulty going onto full bypass in

lateral position. Thoracotomy incision

also made a sternotomy incision

difficult. Repair attempted as mass

closure and protamine given but friable tissue and advanced cancer thus bleeding continued. 


\section{Discussion}

We found that a higher ASA status as well as surgery out of hours as significant factors associated with critical incidents. The most common types of incidents include airway and respiratory (110, 24.9\%) followed by drug related incidents $(67,15.2 \%)$.

The incidents reported in our study represent $0.44 \%$ of cases undertaken - this is relatively low but within reported ranges in the literature. The frequency of incidents reported from individual institutions has varied from $0.28 \%$ to $3.5 \%$ [8]-[13] while higher incidences of up to $12.1 \%$ [14] have also been reported. The difference in figures may be due to the variation in definitions of critical incidents and lack of accepted nomenclature [15] as well as individual perception and ambiguity in application. The relatively low rate of reporting could also be due to underreporting and it is likely that the more serious incidents were captured [16].

\subsection{Characteristics of Incidents}

In our study, the odds of critical incidents increased with ASA status which is consistent with the relationship found by other authors between increasing ASA and risk of critical incidents [14] [17]. ASA 5 status is defined as a moribund patient who is not expected to survive without surgery, thus these patients are at high risk of adverse events.

Critical incidents occurred more frequently out of hours, with an odds ratio of 1.76 (95\% CI: 1.45 to 2.23). This is expected as human factors such as fatigue and a lack of staff become more significant.

From our analysis, emergency surgery did not present increased odds in the incidence of critical incidents compared to elective surgery, although it has been reported to have a slightly higher incidence of critical incidents in literature [14]. A possible reason could be underreporting by junior staff, as emergency cases are more commonly managed by junior staff on call in our institution. Haller et al. [16] suggested that junior staff may underreport due to fear of blame by senior staff.

Critical incidents were more frequent under general anesthesia than regional anesthesia and this was in common with other published studies [10] [12] [17] [19] [20], possibly due to high risk surgeries done under general anesthesia such as cardiothoracic and neurosurgical procedures. However surgeries done under a combination of general anesthesia and regional anesthesia have higher odds for critical incidents than general anesthesia alone. A potential explanation is that surgery that would benefit from a combined technique would have a tendency to be more major surgery.

Patients undergoing monitored anesthesia care only also have a higher odds ratio of critical incidents compared to general anesthesia alone. This may be due to anesthesiologists choosing an MAC technique for sicker patients.

We found that incidents occurred most commonly in the maintenance phase (32.7\%), which is similarly reported in some studies [4] [12]. They were also more common in patients under general surgery which is probably due to larger number of patients admitted under general surgery, associated sepsis and fluid and electrolyte imbalances [4] [6] [12].

The most common type of incident we found in our study was airway and respiratory events which is similar to some studies [11] [21] [22] although others have found cardiovascular incidents to be more common [18], this is likely due to differences in patient population and lack of standardization in types of incidents.

\subsection{Airway and Respiratory Incidents}

Of the 110 airway and respiratory incidents, 41 were dental injuries, and 8 oropharyngeal injuries. Five out of eight of the oropharyngeal injuries were associated with the use of GlideScope videolaryngoscopy (Verathon, Medical Inc., Bothell, WA, USA), and these occurred in 2009 to 2010-corresponding to the introduction of GlideScope to our institution. Subsequent improvement in training with emphasis on keeping direct visual contact with the endotracheal tube as far as possible into the oropharynx [23]-[27], resulted in no incidents of oropharyngeal injury in 2011.

There were 11 reported events of aspiration, which gives us an incidence of aspiration of 1.3 per 10000 general anesthetics, comparable to published data [28]-[31]. While no deaths occurred due to aspiration in our study, death rates in patients who aspirated range from 3.8\% in the Australia Incident Monitoring Study [32], to 4.6\% in the Sweden Study [30]. Some suggested risk factors for aspiration include the urgency of surgery, airway 
problems, inadequate depth of anesthesia, use of the lithotomy position, gastrointestinal problems, depressed consciousness, increased severity of illness and obesity [33].

\subsection{Drug Related}

The second most common type of incident was drug related, accounting for $15.2 \%$ of total reported events. This is consistent with other studies that found drug related incidents as one of the most common errors [4] [11] [19].

Of the 37 incidents with adverse drug reactions: 10 were related to Vancomycin. Vancomycin is given in our institution most commonly when the patient has a penicillin or cephalosporin allergy, or has a known methicillin resistant staphylococcus aureus (MRSA) infection. Vancomycin use has been increasing worldwide due to evolving epidemiology with increase in community acquired MRSA [34]. Reported incidence rates for common adverse reactions of Vancomycin include: an anaphylactoid reaction known as red man syndrome (5\% - 50\%), thrombophlebitis (approximately 40\%), rash (4\% - 6\%), nephrotoxicity (7\% - 8\%), and ototoxicity (4\% - 10\%). True anaphylaxis is exceedingly rare [35]-[38]. The recommended dose of $15-20 \mathrm{mg} / \mathrm{kg}$ [39] [40] should be administered at a maximal rate of $1 \mathrm{~g} / \mathrm{hr}$. to minimize infusion related adverse events [39]. This results in time pressure on the anesthesia provider as prophylactic therapy requires effective levels of antimicrobial present from skin incision. Infusion rates exceeding recommendations could have contributed to the incidents reported, and we should look into improving the timing for starting Vancomycin infusions.

There was one incident of wrong heparin dilution during heparin locking of a central venous catheter for dialysis - this was due to human error and contributed by the different formulations of heparin available in our institution.

In studies on drug errors, human and system factors have been implicated in up to 87\% of errors [41] [42]. Everyday experience would suggest that staff shortages, cognitive overload of members of staff, distractions, poor communication, haste, and fatigue are common contributory factors [43]. Prevention of drug errors must take into account the whole range of factors from those related to patients to organizational systems. Some recommendations in literature [44] include: Improving awareness of errors and establishing a safety culture, reducing system complexity, standardizing packaging, presentation and administration, improving environment and workflow as well as quality assurance and reporting of incidents.

\subsection{Cardiovascular Arrest in Operating Theatre}

Our study found 38 incidents with cardiovascular arrest of which 18 were admitted to ICU and 20 passed away within 24 hours of the incident.

They occurred most frequently in male patients, emergency surgeries and under GA. This is similar to other published studies in perioperative cardiac arrest and mortality [45]-[47]. The higher incidence among males [20] [46] [47] can be explained by the predisposition of men to trauma, violence, and vascular disease compared to women. Of the 20 mortalities, the majority were ASA 4 or 5 and undergoing emergency surgery which is an expected finding.

\subsection{Limitations}

The major limitation with incident reporting is that underreporting will occur in a voluntary system. Data will be an underestimation of true numbers. Underreporting has been attributed to various factors including form design, time constraints, and fear of blame or punitive action, lack of feedback and lack of clarity on what should be reported amongst other reasons [48].

Anesthesiologists also tend to report major adverse events rather than minor events [16]. Different clinicians define critical incidents differently, with variation in perception and reporting [49].

It is also impossible to validate information as it is anonymous. Due to the inherent nature of the data, there are sometimes missing pertinent details or insufficient contextual information. The electronic forms were incomplete in some sections, for which data could mostly be obtained from the descriptive narrative.

Reporting bias also cannot be excluded. When the outcome is known, it influences the reporter's judgement and also the evaluation of the critical incident [14]. As incidents may not fit clearly into one category, classification is varied between different institutions.

Keeping these limitations in mind, we believe trends can be detected which can be used to improve patient 
safety. Critical incident reporting offers many advantages, including the ability to capture "near misses" which are a rich source for learning, and the opportunity to look for recoveries out of dangerous situations in which no harm was done. Incident analysis can lead to root cause of errors and tracking incidents allows monitoring of the process of interventions made over time. The discussion of critical incidents, especially for infrequent events, has clear educational value, and the cost of incident reporting at an institutional value is low.

\subsection{Conclusions}

Our institution has a well-established reporting system that is voluntary, maintains anonymity and has an easy to fill form. They are discussed during regular department meetings, in which significant events are further looked into so that preventive measures can be instituted. However, we still need to work on improving the rate of reporting by encouraging feedback and creating a more conducive environment.

There are institutions that have a mandatory audit form for all anesthetics, to record significant events and critical incidents that occur in the operating theatre. However our institution has developed a post-operative follow-up system since 2011 where major complications are captured and all patients after an anesthetic are followed up postoperatively either via a ward visit or a phone call. This should improve monitoring our anesthesia service for major events.

Critical incident reporting is a valuable part of quality assurance. Identifying and mitigating risk factors associated with patient harm can improve patient safety. Higher ASA status appears to be the most important contributory factor that results in actual or potential patient harm in our study. Also significant, was time of incident, with incidents more likely out of hours. Further improvement at our institution would entail minimizing anesthesia occurring out of hours, and managing human factors such as fatigue that are important during these cases.

We should continue to invest in reporting critical incidents, incident analysis as well as improvement plans to reduce risk, enhance patient safety and preventive strategies to decrease the future occurrence of critical incidents. A national critical incident reporting scheme such as that in UK, Australia and Thailand, may allow for further tracking and analysis of incidents to improve patient safety.

\section{References}

[1] Flanagan, J.C. (1954) The Critical Incident Technique. Psychological Bulletin, 5, 327-358. http://dx.doi.org/10.1037/h0061470

[2] Cooper, J.B., Newbower, R.S., Long, C.D. and McPeek, B. (1978) Preventable Anesthesia Mishaps: A Study of Human Factors. Anesthesiology, 49, 399-406. http://dx.doi.org/10.1097/00000542-197812000-00004

[3] Runciman, W.B. (1988) The Australian Patient Safety Foundation. Anaesthesia and Intensive Care, 18, 98-100.

[4] Webb, R.K., Currie, M., Morgan, C.A., Williamson, J.A., Mackay, P., Russell, W.J. and Runciman, W.B. (1993) The Australian Incident Monitoring Study: An Analysis of 2000 Incident Reports. Anaesthesia and Intensive Care, 21, 520528.

[5] Choy, C.Y. (2008) Critical Incident Monitoring in Anaesthesia. Current Opinion in Anesthesiology, 21, $183-186$. http://dx.doi.org/10.1097/ACO.0b013e3282f33592

[6] Rooksby, J., Gerry, B. and Smith, A.F. (2007) Incident Reporting Schemes and the Need for a Good Story. International Journal of Medical Informatics, 76, 205-211. http://dx.doi.org/10.1016/j.ijmedinf.2006.05.019

[7] National Patient Safety Agency (2005) Seven Steps to Patient Safety: Full Reference Guide. NPSA, London, 100.

[8] Kumar, V., Barcelos, W.A., Mehta, M.P. and Carter, J.G. (1988) An Analysis of Critical Incidents in a Teaching Department for Quality Assurance. Anaesthesia, 43, 879-883. http://dx.doi.org/10.1111/j.1365-2044.1988.tb05606.x

[9] Galletly, D.C. and Mushnet, N.N. (1991) Anaesthesia System Errors. Anaesthesia and Intensive Care, 19, 66-73.

[10] Khan, F.A. and Hoda, Q.A. (2001) A Prospective Survey of Intra-Operative Critical Incidents in a Teaching Hospital in a Developing Country. Anaesthesia, 56, 171-182. http://dx.doi.org/10.1046/j.1365-2044.2001.01528-3.x

[11] Short, T.G., O’Regan, A., Lew, J. and Oh, T.E. (1992) Critical Incident Reporting in an Anesthetic Department Quality Assurance Programme. Anaesthesia, 47, 3-7.

[12] Gupta, S., Naithani, U., Brajesh, S.K., Pathania, V.S. and Gupta, A. (2009) Critical Incident Reporting in Anaesthesia: A Prospective Internal Audit. Indian Journal of Anaesthesia, 53, 425-433.

[13] Freestone, L., Bolsin, S.N., Colson, M., Patrick, A. and Creati, B. (2006) Voluntary Incident Reporting by Anaesthetic Trainees in an Australian Hospital. International Journal for Quality in Health Care, 18, 452-457.

http://dx.doi.org/10.1093/intqhc/mzl054 
[14] Maaloe, R., la Cour, M., Hansen, A., Hansen, E.G., Hansen, M., Spangsberg, N.L., Landsfeldt, U.S., Odorico, J., Olsen, K.S., Moller, J.T. and Pederson, T.L. (2006) Scrutinizing Incident Reporting in Anaesthesia: Why Is an Incident Perceived as Critical? Acta Anaesthesiologica Scandinavica, 50, 1005-1013. http://dx.doi.org/10.1111/j.1399-6576.2006.01092.x

[15] Runciman, W.B. (2002) Lessons from the Australian Patient Safety Foundation: Setting up a National Patient Safety Surveillance System-Is This the Right Model? Quality \& Safety in Health Care, 11, 246-251. http://dx.doi.org/10.1136/qhc.11.3.246

[16] Haller, G., Courvoisier, D.S., Anderson, H. and Myles, P.S. (2011) Clinical Factors Associated with the Non-Utilization of an Anaesthesia Incident Reporting System. British Journal of Anaesthesia, 107, 171-179. http://dx.doi.org/10.1093/bja/aer148

[17] Braz, L.G., Modolo, N.S.P., Mascimento, P., do Nascimento Jr., P., Bruschi, B.A., Castiglia, Y.M., Ganem, E.M., de Carvalho, L.R. and Braz, J.R. (2006) Perioperative Cardiac Arrest: A Study of 53,718 Anesthetics over 9 Years from a Brazilian Teaching Hospital. British Journal of Anaesthesia, 95, 569-575. http://dx.doi.org/10.1093/bja/ael065

[18] Manghanani, P.K., Shinde, V.S. and Chaudhari, L.S. (2004) Critical Incidents during Anaesthesia “An Audit”. Indian Journal of Anaesthesia, 48, 287-294.

[19] Currie, M. (1989) A Prospective Survey of Anaesthetic Critical Events in a Teaching Hospital. Anaesthesia and Intensive Care, 17, 403-411.

[20] Arbous, M.S., Grobboe, D.E., van Kleef, J.W., de Lange, J.J., Spooormans, H.H., Touw, P., Werner, F.M. and Meursing, A.E. (2001) Mortality Associated with Anaesthesia: A Qualitative Analysis to Identify Risk Factors. Anaesthesia, 5, 1141-1153. http://dx.doi.org/10.1046/j.1365-2044.2001.02051.x

[21] Turkistani, A., El-Dawlatly, A.A., Delvi, B., Alotaibi, W. and Abdulghani, B. (2009) Critical Incident Monitoring in a Teaching Hospital. Middle East Journal of Anesthesiology, 20, 97-100.

[22] Charuluxananan, S., Punjasawadwong, Y., Suraseranivongse, S., Srisawasdi, S., Kyokong, O., Chinachoti, T., Chanchayanon, T., Rungreungvanich, M., Thienthong, S., Sirinan, C. and Rodanant, O. (2005) The Thai Anesthesia Incidents Study (THAI Study) of Anesthetic Outcomes: II. Anesthetic Profiles and Adverse Events. Journal of the Medical Association of Thailand, 88, S14-S29.

[23] Cross, P., Cytryn, J. and Cheng, K.K. (2007) Perforation of the Soft Palate Using the GlideScope Videolaryngoscope. Canadian Journal of Anesthesia, 54, 588-589. http://dx.doi.org/10.1007/BF03022329

[24] Vincent Jr., R.D., Wimberly, M.P., Brockwell, R.C. and Magnuson, J.S. (2007) Soft Palate Perforation during Orotracheal Intubation Facilitated by the GlideScope Videolaryngoscope. Journal of Clinical Anesthesia, 19, 619-621. http://dx.doi.org/10.1016/j.jclinane.2007.03.010

[25] Leong, W.L., Lim, Y. and Sia, A.T. (2008) Palatopharyngeal Wall Perforation during GlideScope Intubation. Anaesthesia and Intensive Care, 36, 870-874.

[26] Cooper, R.M. (2007) Complications Associated with the Use of the GlideScope Videolaryngoscope. Canadian Journal of Anesthesia, 54, 54-57. http://dx.doi.org/10.1007/BF03021900

[27] Amundson, A.W. and Weingarten, T.N. (2013) Traumatic GlideScope(®) Videolaryngoscopy Resulting in Perforation of the Soft Palate. Canadian Journal of Anesthesia, 60, 210-211. http://dx.doi.org/10.1007/s12630-012-9824-3

[28] Olsson, G.L., Hallen, B. and Hambracus-Jonzon, K. (1986) Aspiration during Anesthetics. Acta Anaesthesiologica Scandinavica, 30, 84-92. http://dx.doi.org/10.1111/j.1399-6576.1986.tb02373.x

[29] Mellin-Olsen, J., Fastin, S. and Gisvold, S.E. (1996) Routine Preoperative Gastric Emptying Is Seldom Indicated: A Study of 85,594 Anesthetics with Special Focus on Aspiration Pneumonia. Acta Anaesthesiologica Scandinavica, 40, 1184-1188. http://dx.doi.org/10.1111/j.1399-6576.1996.tb05548.x

[30] Warner, M.A., Warner, M.E. and Weber, J.G. (1993) Clinical Significance of Pulmonary Aspiration during the Preoperative Period. Anesthesiology, 78, 56-82. http://dx.doi.org/10.1097/00000542-199301000-00010

[31] Suraseranivongse, S., Valairucha, S., Chanchayanon, T., Mankong, N., Veerawatakanon, T. and Rungreungvanich, M. (2005) The Thai Anesthesia Incidents Study (THAI Study) of Pulmonary Aspiration: A Qualitative Analysis. Journal of the Medical Association of Thailand, 88, S76-S83.

[32] Kluger, M.T. and Short, T.G. (1999) Aspiration during Anesthesia: A Review of 133 Cases from the Australian Anaesthetic Incident Monitoring Study (AIMS). Anaesthesia, 54, 19-26. http://dx.doi.org/10.1046/j.1365-2044.1999.00642.x

[33] Ng, A. and Smith, G. (2001) Gastroesophageal Reflux and Aspiration of Gastric Contents in Anesthetic Practice. Anesthesia \& Analgesia, 93, 494-513.

[34] Pereira, L.A. and Fisher, D.A. (2008) Methicillin-Resistant Staphylococcus aureus Control in Singapore-Moving Forward. Annals of the Academy of Medicine, Singapore, 37, 891-896. 
[35] Sorrell, T.C. and Collignon, P.J. (1985) A Prospective Study of Adverse Reactions Associated with Vancomycin Therapy. Journal of Antimicrobial Chemotherapy, 16, 235-241. http://dx.doi.org/10.1093/jac/16.2.235

[36] Mellor, J.A., Kingdom, J., Cafferkey, M. and Keane, C.T. (1985) Vancomycin Toxicity: A Prospective Study. Journal of Antimicrobial Chemotherapy, 15, 773-780. http://dx.doi.org/10.1093/jac/15.6.773

[37] Savarese, A., Nanni, M.L., Pasquali, C. and Egidio, A.C. (1999) Vancomycin Prophylaxis in Joint Arthroplasty. La Chirurgia degli Organi di Movimento, 84, 247-251.

[38] Wazny, L.D. and Daghigh, B. (2001) Desensitization Protocols for Vancomycin Hypersensitivity. Annals of Pharmacotherapy, 35, 1458-1464. http://dx.doi.org/10.1345/aph.1A002

[39] Alexander, J.W., Solomkin, J.S. and Edwards, M.J. (2011) Updated Recommendations for Control of Surgical Site Infections. Annals of Surgery, 253, 1082-1093. http://dx.doi.org/10.1097/SLA.0b013e31821175f8

[40] Hafermann, M.J., Kiser, T.H., Lyda, C., Fish, D.N., Barber, G.R., Wempe, M.F. and Cleveland Jr., J.C. (2014) Weight-Based versus Set Dosing of Vancomycin for Coronary Artery Bypass Grafting or Aortic Valve Surgery. The Journal of Thoracic and Cardiovascular Surgery, 147, 1925-1930. http://dx.doi.org/10.1016/j.jtcvs.2013.12.037

[41] Toff, N.J. (2010) Human Factors in Anaesthesia: Lessons from Aviation. British Journal of Anaesthesia, 105, 21-25. http://dx.doi.org/10.1093/bja/aeq127

[42] Bion, J.F., Abrusci, T. and Hibbert, P. (2010) Human Factors in the Management of Critically Ill Patient. British Journal of Anaesthesia, 105, 26-33. http://dx.doi.org/10.1093/bja/aeq126

[43] van Beuzekom, M., Boer, F., Akerboom, S. and Hudson, P. (2010) Patient Safety: Latent Risk Factors. British Journal of Anaesthesia, 105, 52-59. http://dx.doi.org/10.1093/bja/aeq135

[44] Mahajan, R.P. (2011) Medication Errors: Can We Prevent Them? British Journal of Anaesthesia, 107, 3-5. http://dx.doi.org/10.1093/bja/aer131

[45] Tiret, L., Desmonts, J.M., Hatton, F. and Vourc'h, G. (1986) Complications Associated with Anesthesia-A Prospective Survey in France. Canadian Anaesthetists' Society Journal, 33, 336-344. http://dx.doi.org/10.1007/BF03010747

[46] Newland, M.C., Ellis, S.J., Lydiatt, C.A., Peters, K.R., Peters, K.R., Tinker, J.H., Romberg, D.J., Ullrich, F.A. and Anderson, J.R. (2002) Anesthetic-Related Cardiac Arrest and Its Mortality: A Report Covering 72,959 Anesthetics over 10 Years from a US Teaching Hospital. Anesthesiology, 97, 108-115. http://dx.doi.org/10.1097/00000542-200207000-00016

[47] Lienhart, A., Auroy, Y., Péquignot, F., Benhamou, D., Warsgawski, J., Bovet, M. and Jougla, E. (2006) Survey of Anesthesia-Related Mortality in France. Anesthesiology, 105, 1087-1097. http://dx.doi.org/10.1097/00000542-200612000-00008

[48] Mahajan, R.P. (2010) Critical Incident Reporting and Learning. British Journal of Anaesthesia, 105, 69-75. http://dx.doi.org/10.1093/bja/aeq133

[49] Smith, A.F., Goodwin, D., Mort, M. and Pope, C. (2006) Adverse Events in Anaesthetic Practice: Qualitative Study of Definition, Discussion and Reporting. British Journal of Anaesthesia, 96, 715-721. http://dx.doi.org/10.1093/bja/ael099 